\title{
El matrimonio como espacio de "desfragmentación" entre mapuche-huilliches desnaturalizados a Santiago de Chile durante la segunda mitad del siglo XVII (1669-1678)
}

\author{
Marriage as a space of "defragmentation" on the displaced \\ mapuche-huilliche in the city of Santiago, Chile, during the \\ second half of the seventeenth Century (1669-1678)
}

Jaime Valenzuela Márquez ${ }^{1}$

\begin{abstract}
Resumen
A lo largo del siglo XVII la guerra fronteriza en el sur de Chile se caracterizó por las razias orientadas al pillaje y captura de indios declarados legalmente esclavizables desde 1608. Deportados hacia Chile central, Coquimbo o Lima, los mapuches y huilliches meridionales se inscribirán, así, en una generalizada experiencia de desarraigo comunitario, fragmentación de redes sociales, de los vínculos territoriales y, sobre todo, destrucción de lazos familiares; marcas que acompañarán los avatares de aquellos individuos sometidos a las traumáticas experiencias del rapto violento y destierro perpetuo desde sus lugares de origen.

El objetivo de este artículo es delinear los indicios de dicha fragmentación y, luego, estudiar las tendencias de recomposición -o "desfragmentación"- que se observan entre estos indígenas al vincularse en matrimonio, en el contexto urbano de la capital chilena y su comarca. El análisis se sustenta en los registros de la parroquia del Sagrario y se sitúa en una coyuntura histórica de transición entre el auge de captura y tráfico de indios "rebeldes", y la abolición de su esclavitud legal.
\end{abstract}

Palabras claves: esclavitud indígena, Guerra de Arauco, migraciones, Santiago de Chile, vínculos matrimoniales.

\begin{abstract}
Throughout the seventeenth century the frontier war in Southern Chile was characterized by raids that were oriented towards pillage and the capture of indigenous peoples who had been declared to be legally enslavable since 1608. Deported to central Chile, Coquimbo or Lima, Mapuche and southern Huilliche were part of a generalized experience of communal uprooting, the fragmentation of social networks, territorial links and above all the destruction of familiar ties of individuals who were exposed to the traumatic experiences of violent abduction and perpetual exile from their homeland.

The objective of this article is to delineate the signs of this fragmentation and to then study the recomposition trends - or "defragmentation"- that were observed among the Indians upon marriage, within the urban context of the Chilean capital and the surrounding area. This analysis is based on records from the Sagrario parish and centers around an historical moment of transition between the rise of the capture and traffic of this "rebel" Indians and the abolition of legal slavery.
\end{abstract}

Keywords: Indigenous slavery, Arauco War, Migrations, Santiago de Chile, Marriage ties.

Recibido: 6 abril 2016. Aceptado: 19 septiembre 2016

1 Instituto de Historia, Pontificia Universidad Católica de Chile, Casilla 306, Correo 22. Santiago, CHILE. Email: jvalenzm@uc.cl 


\section{Guerra, esclavitud, migraciones indígenas y la ciudad de Santiago}

A partir de las primeras resistencias que encontraron en su avance por la costa y los llanos de Arauco, los españoles comenzaron a reproducir en Chile las estrategias represivas y prácticas esclavistas que venían implementando desde sus primeros pasos por las Antillas caribeñas. Prácticas que cobrarían renovado impulso a partir de la guerra hispano-mapuche desatada con el enfrentamiento de Curalaba, que costó la vida al gobernador del reino en 1598; y, luego, con la cédula real que en 1608 autorizó la captura y transacción legal de los indios "de arriba" -al sur del río Biobío- que se mantuviesen en "guerra viva" (Jara, 1984 [1961]).

Con esta decisión de la Corona, la experiencia del secuestro, deportación, venta y esclavización de indios e indias "de arriba" o "de tierra adentro" -mapuches araucanos, huilliches osorninos y valdivianos, e incluso puelches y chonos (atacados desde Chiloé o Valdivia) - no solo adquirió una legitimación jurídica, sino que además se transformó en el verdadero motor de la Guerra de Arauco - a través de las razias "guerrilleras" y esclavistas denominadas malocas- y en el principal objetivo tanto de los soldados fronterizos como de sus aliados indígenas.

A la "desnaturalización" como objetivo político -destierro del enemigo desde su tierra de origen a zonas bajo control colonial- se unirá entonces la esclavitud como objetivo económico. Dinámica que asumirá características específicas en el contexto de la ciudad de Santiago a mediados de la centuria, enfrentada a una fuerte disminución de mano de obra producto del terremoto que asoló la capital en 1647, de otro sismo en 1657 y de las subsecuentes pandemias de viruelas y tifus que se sucedieron hasta al menos la década de 1670; a lo que se sumaba la constante fuga y amestizamiento de los indios de encomienda, lo que tendió a debilitar el papel que antes jugaba esta institución como factor productivo rural y proveedora de servidumbre urbana. Frente a este panorama de oferta laboral limitada, las décadas posteriores a 1660 muestran un período de demanda creciente de mano de obra para la reconstrucción de la infraestructura urbana - pública y privada- y para los servi- cios domésticos asociados a la expansión de la ciudad y de sus grupos hispanocriollos (De Ramón, 2000; Valenzuela Márquez, 2014b, pp. 628-630).

Nuestro estudio se inserta en una coyuntura que articula dos tendencias opuestas en este contexto de contienda y tráfico esclavista: por una parte, su maduración y refuerzo y, por otra, su decadencia o metamorfosis. Tensión que podríamos delimitar en su inicio con la guerra hispano-mapuche de 16551662 , de particular virulencia, que reactivó la captura y tráfico de indios así como los fundamentos esgrimidos por los actores locales para llevarlo a cabo. Pero que, al mismo tiempo, coincidió con el comienzo de una política abolicionista de amplitud imperial, que abarcó también otros espacios fronterizos como el norte de México, Filipinas y los llanos de Colombia y Venezuela, donde también se practicaba la esclavitud indígena (Reséndez, 2017). Para el caso chileno, esta tendencia fue inaugurada por Felipe IV en 1656 (paradojalmente, en pleno desarrollo del gran alzamiento de esos ańos), continuada a través de diversas cédulas dictadas durante la década siguiente y coronada con la cédula de 1674 que pretendió la abolición definitiva (Hanisch, 1981; Valenzuela Márquez, 2009).

Pese a la tendencia legal que marcaba Madrid, lo cierto es que buena parte de estas disposiciones coincidieron con un refuerzo de las malocas y del tráfico de indios esclavos hacia Chile central y la región agrominera de Coquimbo. Coincidencia directamente relacionada con dos de los gobernadores que más incidencia tuvieron en su mantención e incentivo: Francisco de Meneses (1664-1668) y Juan Henríquez (1670-1682). Ambos se caracterizaron, además, por incrementar las razias ya no solo contra indios hostiles, sino también contra parcialidades de "amigos". El gobernador Henríquez, por su parte, actuó diligentemente para dilatar la promulgación de la cédula de 1674 y evitar, además, la liberación de los indios esclavizados con anterioridad. De hecho, finalmente la Corona cedió a las presiones locales y en 1686 optó por confirmar la práctica del "depósito", que mantenía a los exesclavos con sus antiguos amos o los reasignaba a otros en calidad de encomendados (Jara y Pinto, 1982-1983, I, pp. 319-351; Obregón y Zavala, 2009). 
Junto con la esclavitud, y como parte del conjunto de indios "de arriba" que migrarán forzadamente hacia el norte del Biobío, debemos considerar la arraigada costumbre, generalizada en el conjunto de la sociedad hispanocriolla, de "sacar" niñas o muchachos indios para trasladarlos a otro lugar a trabajar en diversas tareas, sin ningún sustento jurídico; eran simplemente "tomados" y "llevados" por algún español desde la frontera araucana, desde Chiloé o desde regiones cercanas pero ya colonizadas, como Chillán o Maule. Desde muy temprano, también, los soldados fronterizos se dieron a esta práctica ilegal, "sacando" indios de entre los mismos colaboradores que habitaban cerca de los fuertes, llevándolos para su servicio en sus periplos de desertores o durante los permisos invernales hacia Chile central (Contreras Cruces, 2017). También eran intercambiados a las familias por algún objeto o comida con la eufemística fórmula de "venta a la usanza". En la misma lógica, por ejemplo, se engañaba a indios adultos mediante promesas laborales que luego no se cumplían y que terminaban transformándose en adscripciones laborales forzadas. Prácticas que venían asentándose incluso antes del alzamiento de 1598 , como comentaba el gobernador Óńez de Loyola el mismo año en que murió en la emboscada de Curalaba:

Hay otra causa de disminución de estos naturales, de no menos consideración, causada por todo estado de gentes, así eclesiásticas como seculares, que es una saca ordinaria de indios y indias, muchachos y muchachas, que de este obispado [de la Imperial] bajan al de Santiago, tierra de diferente temple, por todos los medios que humanamente se puede aprovechar, hasta robarlos en las calles y en los campos, y embarcarlos en el puerto de Valdivia. Y como navío de negros se han llevado al puerto de Santiago. Y muchas veces la mujer que iba al recaudo de su amo a su hacienda, dejando al marido y a los hijos, ha remanecido navegando la mar. Y era con tanto exceso esto que los vendían públicamente, a trueco de ropa y caballos, cotas y otras cosas. Y los vecinos y moradores de estas ciudades de arriba hacían presentes a sus amigos y conocidos de la de Santiago, caso bien digno de llorar (Carta del gobernador
García Óñez de Loyola al rey, Concepción, 12 enero 1598, en Amunátegui Solar, 1910, II, pp. 149-159).

Estamos, pues, ante un fenómeno migratorio complejo y polifacético -si bien atravesado por un denominador común- y cuya magnitud es difícil de cuantificar. Aunque la evidencia cualitativa permite una idea de la dimensión que iba alcanzando el fenómeno, como se puede ver, por ejemplo, en los testimonios de la propia élite del distrito de la capital, que se mostró temerosa ante el creciente número de aucaes -indios rebeldes- desterrados desde Valdivia y Osorno durante la guerra desatada en 1598 (Domingo de Eraso, 4 enero 1600, cit. Jara, 1984 [1961], p. 180). Por su parte, y poco después de promulgada la cédula que en 1608 había autorizado la esclavización, un oidor de la Audiencia informaba que junto con unos mil ochocientos indios tributarios existentes en el distrito de Santiago, ${ }^{2}$ existirían otros mil que serían aucaes capturados en el sur (Gabriel de Celada, 6 enero 1610, cit. Zúñiga, 2002, p. 94). Y ya durante el período que interesa a este artículo, las partidas de bautismo de la misma parroquia del Sagrario que enmarca nuestro estudio muestran que en una década tan significativa como 1665-1675, el bautismo de indios "de arriba" que poseían la categoría de esclavo o auca se alzó a un promedio cercano al 30\% anual del total de indios bautizados de la ciudad (Valenzuela Márquez, 2014b, pp. 628-629).

A partir de los indicios de la fragmentación individual que conllevan las capturas, destierros y transformación en "piezas" esclavas de aquellos mapuches y huilliches de Chile meridional, este artículo busca examinar las tendencias de recomposición -o "desfragmentación"- que se observan entre ellos al vincularse en matrimonio (entre sí o con otros sujetos), en el contexto urbano de la capital chilena y su comarca (Figura 1).

2 El corregimiento de Santiago -sus “términos”- estaría delimitado de la siguiente manera: por el norte, el valle de Colina; por el sur, el río Maipo (incluyendo los pueblos indios de Llupeo, Talagante y Maipo); por el poniente, Pudahuel y la cadena de cerros de la cordillera de la Costa (incorporando los pueblos de Huechún, Lampa y Pelvín); y por el oriente, los faldeos de los Andes (De Ramón, 1978, p. 74; Zúñiga, 2002, p. 95). 


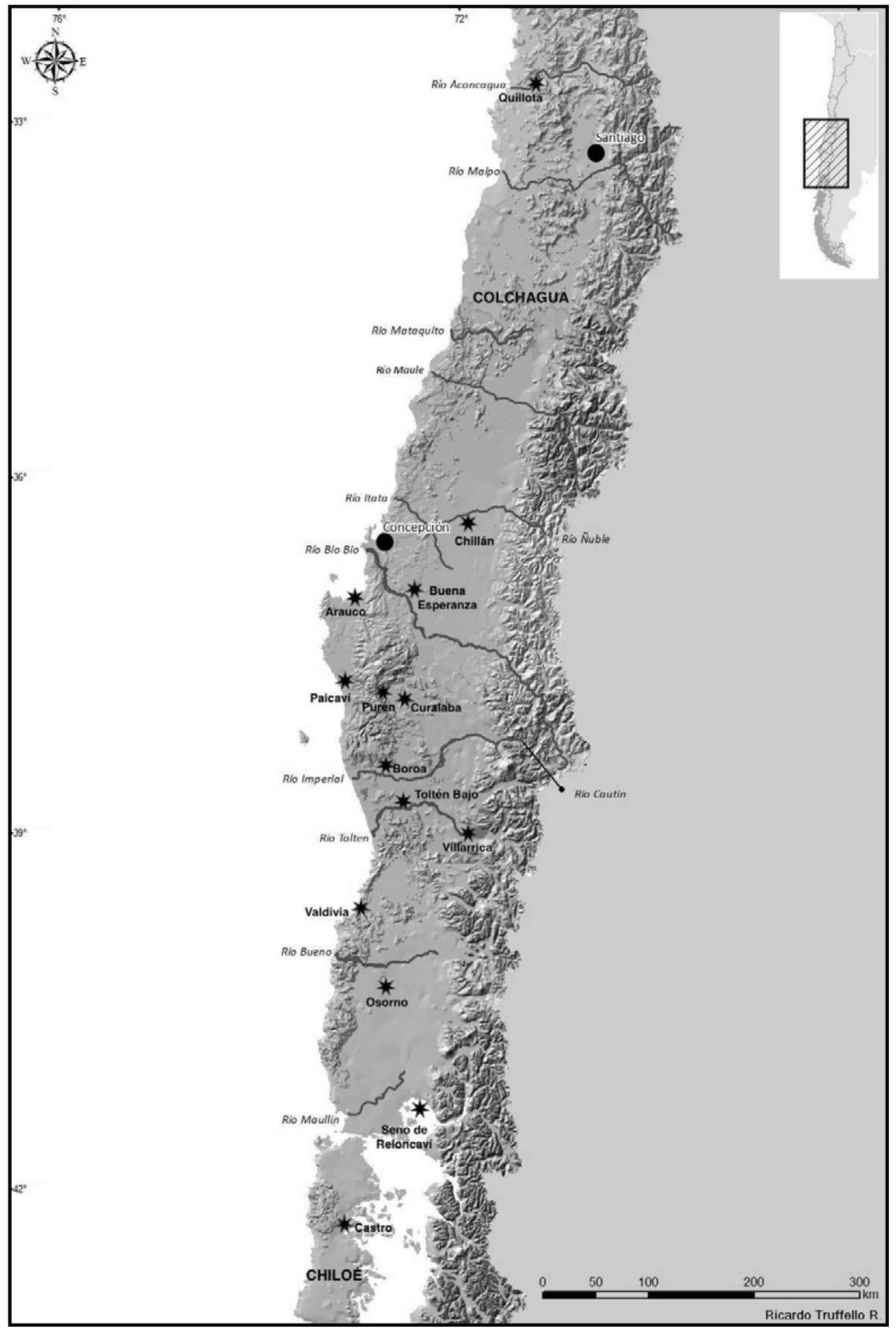

Figura 1. Lugares citados [Elaboración: Jaime Valenzuela. Cartografía: Ricardo Truffello]. 


\section{El matrimonio católico, la libertad de los contrayentes y sus posibilidades amerindias}

La normativa emanada del Concilio de Trento (1545-1563) enmarcó el matrimonio religioso en el panorama más amplio de refrendación y refuerzo del papel jugado por los sacramentos católicos frente a los cuestionamientos protestantes, validándolos como ritos de eficacia objetiva y no solo como actos exteriores o simples signos de pertenencia al mundo cristiano (Delumeau y Cottret, 1996, p. 78; Lacoste, 1998, pp. 696-700). En esta perspectiva, Trento cambió profundamente la situación existente con anterioridad, y lo hizo en dos direcciones: llevando el matrimonio al interior del templo y buscando desplazar -hasta anularla canónicamente- la costumbre del noviazgo y los compromisos familiares y relaciones premaritales que lo acompańaban, y que generaban un ambiguo y extenso preludio a la unión canónica propiamente tal. La decisión de Trento apuntaba a hacer seguro y manifiesto el paso de una persona al estado de cónyuge, por lo que en adelante las bodas debían celebrarse en la iglesia parroquial y hacerse públicas en la respectiva comunidad con la debida antelación; y, junto con ello, debían registrarse oportunamente en una recopilación de actos oficiales (los libros parroquiales).

Desde Trento, pues, los diferentes ritos de paso que con anterioridad iban armando las alianzas familiares que sustentaban el posterior matrimonio serían ahora sustituidos por un único gesto ritual válido, "un sacramento que en el momento mismo en que tenía lugar cambiaba bruscamente el status de quien lo practicaba”, en forma similar a lo acontecido con el bautismo (Prosperi, 2008, p. 116). El matrimonio ante el sacerdote buscará imponerse así como el rito parroquial que debía marcar el inicio de la vida conyugal en la formalidad de lo escrito y de la ceremonia pública; y que estaba en función, además, de la preocupación mayor que tenía la Iglesia sobre el modelo de familia -hijos legítimos versus hijos naturales, por ejemplo-y las prácticas sexuales -bigamia, sexualidad premarital o extramatrimonial, etc.- y sobre la base de la predilección explícita que otorgaba la Iglesia a la virginidad y al celibato por sobre el estado conyugal (Delumeau y Cottret, 1996, p. 79).
Se trata de una perspectiva que sin duda demoraría en hacerse una realidad efectiva y generalizada, existiendo cantidad de testimonios que muestran, por ejemplo, la persistencia entre el campesinado europeo de la costumbre de casarse solo después de largos períodos de convivencia (Prosperi, 2008, p. 117; Goody, 1986). Pero Trento sin duda que establece una opción moderna de construcción marital, en el sentido de que privilegia explícitamente el indispensable consentimiento individual de los contrayentes (que ya venía siendo normado desde el siglo XI) en detrimento de las decisiones tomadas por otros, sus familias, por ejemplo.

Esta "libertad" de elección y de consentimiento de los cónyuges fue algo que también se buscó y se normó para el contexto americano en que se forjó la representación teológica de sus habitantes indígenas durante el siglo XVI (Latasa, 2008 y 2016; Ghirardi e Irigoyen López, 2009). Los concilios americanos, como el mexicano de 1585, recogieron esta tradición renovada por Trento justamente para intentar limitar la violencia que se desató desde un comienzo sobre las comunidades amerindias y que, en el plano que estudiamos, conllevó abusos de todo tipo en la reconfiguración social, familiar y espacial en función de los intereses de los colonizadores. Pero los autores coinciden, no obstante, en que frente a otros abusos más graves el tema del libre consentimiento en el matrimonio indígena no formaba parte de las prioridades (Martínez Ferrer, 2011, p. 102); aunque sí lo era en relación con la obsesión eclesiástica de que los nuevos cristianos americanos formaran sus familias, se comportaran sexualmente y criaran a sus hijos conforme a los preceptos morales oficiales. Y en este sentido cobró importancia la labor pedagógica de la catequesis orientada -entre otros objetivos "civilizatorios"- a cambiar hábitos de la vida privada y erradicar prácticas poligámicas en sociedades que rápidamente mutarían hacia el mestizaje biológico y la hibridación cultural (Gruzinski, 1980; Ragon, 1992; Martini, 1993, pp. 206-212).

En todo caso, con respecto al papel de los cónyuges en la generación del vínculo, es claro que más allá del ideal jurídico y de la formalidad del derecho, como en muchos otros aspectos, la realidad cotidiana americana los desafiaba en abierta contradicción, al imponer los usos arbitrarios que eran intrínsecos 
al ejercicio de la dominación y subordinación que alimentaba la relación hispano-indígena-africana durante todo el período. En contextos como el mexicano o el peruano, por ejemplo, el matrimonio de indígenas conjugaba tensiones entre las presiones de encomenderos, curas y caciques, quienes pugnaban por interferir en las uniones para beneficiarse de sus resultados o evitar perjuicios en las obligaciones tributarias o políticas (cf. Vicuña Guengerich, 2015). Podemos acercarnos, así, a tratadistas como el jesuita José de Acosta, que cumplió un papel central en la aplicación de las normas tridentinas para el mundo andino durante el III Concilio Limense (1583-1584). Al analizar el mundo indígena y buscar estrategias para su conversión, Acosta se ocupó brevemente del matrimonio para describir los errores que habría que corregir en las creencias erradas y costumbres heredadas que se relacionaban con la experiencia marital, destacando los abusos que tradicionalmente cometían los curacas y poderosos de las comunidades, entre otras cosas, en la configuración de las parejas y las subsecuentes alianzas familiares (Acosta, 1987 [1576], II, pp. 459-467).

En este sentido, si revisamos otros textos que en la época se refieren a casamientos de indios y otros sacramentos -catecismos, tratados y manuales para uso pastoral, confesionarios, etc.-, veremos que la mayor parte de sus preocupaciones son respecto de indios insertos en el espacio subalterno que les definía el mundo colonial, sometidos (al menos en términos físicos) y avecindados en espacios más o menos controlados por los europeos y, por lo tanto, adscritos al sistema legal indiano y a la jurisdicción de la Iglesia (cf. Lavrín, 1991; Inostroza Ponce, 2013). Es decir, indios tributarios o "reducidos", incorporados formalmente como súbditos de la monarquía y nuevos cristianos, para los cuales se fueron elaborando una serie de normas que apuntaban a sus derechos y obligaciones en el marco de la dominación colonial. Escritos como el de Acosta se preocuparon, pues, de describir y evaluar las dificultades y proponer los medios para evangelizarlos, apuntando sus críticas como también lo hicieron funcionarios y juristas de la época- a las heterodoxias e "inmoralidades" de los catecúmenos, por un lado; $y$, por otro, a los abusos de las autoridades comunitarias, de los encomenderos hispanos y de los curas doctrineros que, entre otras cosas, llegaban a cobrar derechos excesivos por los casamientos indígenas (Matienzo, 1967 [1567], pp. 331-333; Lamana Ferrario, 2012).

\section{El matrimonio y los indios aucaes de Chile meridional}

Respecto de los otros indios, los "bárbaros" e "infieles" que aún se mantenían hostiles en distintas fronteras del continente, la representación era muy diferente a la que hemos descrito en el acápite anterior (Lázaro Ávila, 1997; Bernabéu, 2010; Giudicelli, 2011). Ya en contextos como el de Chile central, la lejanía de los centros administrativos y la consiguiente autonomía relativa de los encomenderos-terratenientes, unida a la fragmentación comunitaria e imposición de la encomienda de servicio personal en esa zona del país (cf. Contreras Cruces, 2009), hacían que sacramentos con connotaciones sociales y consecuencias jurídicas como el matrimonio de los indios fuese un acto de ejercicio claramente colonial; esto es, un rito donde la capacidad de decisión y la propia generación de un vínculo previo entre los contrayentes podían verse limitadas o incluso subsumidas por las decisiones de sus "amos".

Esta realidad se veía acentuada en el caso de aquel universo humano que habitaba al sur del río Biobío y que por el hecho de protagonizar una situación de guerra fronteriza permanente se le había clasificado en el marco de una barbarie endémica y se le representaba como enemigo del Estado y de la religión (Obregón Iturra, 2010); enemigo que, por cierto, vivía en un estado de autonomía política y cultural que impedía cumplir con la obsesión imperial y eclesiástica de imponer en todos los rincones de la soberanía castellana la "vida en policía" -es decir, ajustada a las normas de la Corona y de la Iglesia-.

Como sucedía con otros amerindios de espacios fronterizos donde no se había logrado la dominación occidental -como en la zona de los grandes lagos del Canadá o el norte de Nueva España (Hausberger, 2004; Osante, 2010; Valenzuela Márquez, 2016)-, la actividad misionera que buscaba su cristianización y, por medio de ella, su integración al universo de los indios coloniales, debió contentarse 
con limitadas acciones y magros resultados. En los terrenos inhóspitos de la Araucanía o en los llanos más meridionales de "tierra adentro", los jesuitas apenas pudieron desplegar algunas estrategias de su reconocida accommodatio, contentándose con efímeras misiones volantes que apenas permitían aplicar un bautismo de limitada eficacia simbólicoritual (Foerster, 1996; Valenzuela Márquez, 2011).

En segundo plano se mantenía, claro, el objetivo de casar cristianamente a aquellos "bárbaros" y tratar de inculcar a los nuevos esposos una moral conforme a sus criterios doctrinales. Pero como también se daba en buena parte del continente no controlado por los ibéricos, la poliginia seguía constituyendo uno de los grandes problemas a los que se enfrentaron los agentes cristianizadores, siendo una de las costumbres originarias que más dificultades presentó para imponer la ortodoxia del matrimonio monogámico exigido por la Iglesia (Martini, 1993, p. 206; Pizzigoni, 2004). Así sucedió, por cierto, durante la actividad misionera al sur del Biobío con el sistema de vinculación poligámica mapuche, que en aquel contexto autonómico solo generaba frustración y desesperanza entre los sacerdotes.

Vale la pena detenerse un momento a observar esta sociedad familiar mapuche que -siguiendo a Guillaume Boccara- presentaría una estructura con mecanismos políticos, sociales, económicos y territoriales complejos que iban más allá de una forma "segmentada" o "acéfala", sino que apuntaban más bien a un sistema de redes maleables y adaptables a la variación de las condiciones comunitarias. A nivel familiar, ello se traducía en la existencia de una familia polígama constituida en el seno de la choza o ruca (una rucatuche); unidad básica que se insertaba, a su vez, en un conjunto de rucas habitadas por otros miembros de la parentela, conformando un caserío patrifamiliar -familia polígama dependiente- enlazado por un agregado familiar más amplio definido por los miembros masculinos ligados por ascendencia en línea paterna, pero donde también podían residir cuñados y yernos. A su vez, una agrupación de patrifamilias, unidas a caseríos aliados conformarían un quiñelob, estructurado como un grupo local endógamo a nivel de sus relaciones matrimoniales y familiares, y que constituye el pri- mer nivel político autónomo de la estructura social mapuche: la comunidad endogámica de base al interior de la cual sus miembros se casan y cooperan en las actividades de producción. La base familiar de la ruca, por su parte, la componen el marido y su(s) esposa(s), así como sus hijas e hijos solteros; pero también se amplía al albergar a algunos hijos casados con su respectiva descendencia, con lo que la ruca pasa a ser el hábitat de una familia polígama extendida. Por su parte, el número de esposas se hallaría definido en función del estatus social del esposo; y, con respecto a la movilidad espacial, normalmente los hijos varones que dejaban las rucatuche de su infancia se instalaban en el seno de otra patrifamilia, pero siempre dentro de su quiñelob y cercano a su patrifamilia originaria; mientras que las hijas que se casaban pasaban a habitar, teóricamente, en la patrifamilia de sus esposos (Boccara, 2007 [1998], pp. 31-34; cf. Goicovich, 2003).

Como vemos, la familia polígama jugaba un papel central como base de alianzas políticas y sustento económico del mundo mapuche, y su ramificación endogámica mantenía una tupida malla de filiación parental que sin duda sería destruida con la eventual imposición de un matrimonio cristiano y de una familia de estilo occidental. Y es justamente esta perspectiva la que permite apreciar en su justa dimensión el impacto que pudieron tener las razias maloqueras en la desestructuración de las familias organizadas al interior de los quinélob, destruyendo rucas, quemando siembras, dando muerte a hombres adultos, capturando niños, jóvenes y, sobre todo, mujeres -claves en el desmembramiento y fragmentación de las unidades domésticas y comunitarias-, que de esta manera brutal vivían un rito de paso radical hacia un nuevo estatus (cf. Flusche y Korth, 1983). Ya a fines de 1590 el obispo de La Imperial se quejaba ante el rey por la conducta incontrolada de los soldados en las incursiones esclavistas a tierra adentro, donde no tenían ningún cuidado en quebrar familias y matrimonios indígenas al atomizar las comunidades en "piezas sueltas" funcionales a su tráfico: "[...] y acontece muchas veces que dejando al indio casado le llevan la mujer, y otros al contrario; y otras veces llevan indios e indias de poca edad, y los quitan a sus padres, y muchos soldados llevan indias para servirse mal de ellas" (Carta del 
obispo de La Imperial al rey, 17 diciembre 1590, en Medina, 1956-1982, VII, pp. 124-125).

Destruido el lazo esencial de la rucatuche en medio de la violencia armada de los soldados y de sus indios aliados que se repartirían el codiciado botín, los sobrevivientes de la maloca vivirán un proceso de fragmentación generalizada de sus referentes de identidad social y espacial, dilución violenta de sus redes de protección y una aislación individual que los transformará rápidamente en "piezas" transables y deportables a lugares extraños, en función de los deseos de sus captores, traficantes o de los nuevos amos de aquellos lugares alejados hacia donde serán desplazados.

En este nuevo escenario de desnaturalización esclavista, la Iglesia actuaba con mayor comodidad y en condición dominante, pudiendo aplicar los sacramentos católicos en sujetos desarraigados, sin capacidad de resistencia e insertos en las dinámicas propiamente coloniales de la sociedad hispana. En este sentido, el matrimonio cristiano constituye, en sí, un acto que puede ser parte de esta ruptura violenta con el pasado originario y un gesto de incorporación subordinada a las reglas coloniales, toda vez que en el contexto de destierro y re-arraigo forzado en una nueva realidad ajena y extraña, simboliza el triunfo de la monogamia y el despojo de cualquier unión previa y autónoma que podrían haber tenido los nuevos cónyuges en su vida anterior. Como destaca Pierre Ragon refiriéndose a la generalidad americana, "al tocar las relaciones matrimoniales y las prácticas sexuales, los españoles arremeten contra un elemento esencial de la organización social" (Ragon, 1992, p. 12). Es un rito, por tanto, que refuerza simbólica y socialmente el triunfo sobre las costumbres "bárbaras" e "infieles" con las que vivían "tierra adentro" y una refrendación de la nueva situación en la que se hallaban sumidos. El matrimonio, entonces, al igual que el bautismo en otro sentido, puede ser visto como una contribución a la fragmentación y, al mismo tiempo, como ese espacio privilegiado en que se articulan las posibilidades de "desfragmentación" que se ofrecen a estos sujetos en el nuevo contexto al que se ven sometidos.

\section{La parroquia del Sagrario y los ma- trimonios de indios "de arriba" en Santiago}

Antes de seguir con el hilo de nuestra demostración conviene hacer una pausa para dar cuenta de las fuentes que sustentan el análisis. Santiago contó desde 1547 con la parroquia del Sagrario, establecida en la iglesia mayor, y donde se llevaba a cabo toda la administración de sacramentos para españoles, indios y "castas" hasta 1635, cuando comienza a funcionar la parroquia de Santa Ana, y cuya jurisdicción abarcará ahora el sector poniente de Santiago. No obstante, los registros de matrimonios indígenas de esta última son muy fragmentarios, dispersos y en ocasiones más bien tardíos, por lo que la escasa información que proporcionan solo fue utilizada de manera complementaria y sin mayor incidencia en la propuesta. ${ }^{3}$ Lo mismo ocurre con los registros matrimoniales de las otras tres parroquias que comienzan a funcionar en la segunda mitad del XVII y que, por coincidir con el período de nuestro interés, podrían haber aportado información valiosa a la investigación: Renca, al otro lado del río Mapocho, hacia el norte (1662); Nuñoa, en la periferia rural hacia el este (1662); y San Isidro, en la periferia rural hacia el sur (1686). ${ }^{4}$

Estamos conscientes de que los registros matrimoniales no constituyen un sustento documental completamente "objetivo" para determinar tendencias definitivas y contundentes respecto de una historia de los vínculos de pareja en la perspectiva de una demografía histórica. No solo se trata de una fuente que presenta las mismas debilidades que los estudiosos han detectado, por ejemplo, en los libros de bautismo a lo largo de la América colonial (Konetzke, 1946; Mellafe, 1986; Rabell, 1990); sino que también deja afuera las innumerables uniones

3 AAS, Santa Ana, Libro de bautismos y matrimonios, vol. 1 (fragmentos, 1641-1657); Libros de matrimonios, vol. 1 (fragmentos, 1695-1726).

4 AAS, Renca, Libros de bautismos, vol. 1 (bautismos, matrimonios y entierros: fragmentos de matrimonios, 1668-1676 y 1693); Libro de matrimonios, vol. 1 (fragmentos de matrimonios, 1676-1693). AAS, Nuńoa, Libros de matrimonios, 1 (1670-1799). AAS, San Isidro, Libros de matrimonios, vol. 1 (fragmentos, 1693$1694, \ldots)$. 
extramaritales que alimentaban la práctica generalizada del concubinato y cuyos indicios más evidentes se daban, justamente, en la recurrencia de hijos ilegítimos registrados al ser bautizados. Amancebamiento e ilegitimidad que serían aún más comunes en espacios urbanos, marcados por la concentración demográfica y la diversidad socioétnica (Calvo, 1984); al contrario de localidades indígenas con mayor integración e historia comunitaria, y donde los sacramentos y rituales católicos pasarían a formar parte de las prácticas cotidianas y regulares en la vida personal y en la cohesión social de sus habitantes (Inostroza Ponce, 2014). No obstante, para efecto de nuestras hipótesis y del problema al cual buscamos dar respuesta, creemos que dichos registros entregan suficientes indicios para dar cuenta de algunas tendencias en determinados comportamientos que involucran a aquellos indios del sur que pasan por el rito formal del matrimonio cristiano en un contexto de control hispano como es la principal parroquia de la capital de Chile; y, por lo tanto, pensamos que los libros de matrimonios, como el resto de registros parroquiales, permiten avanzar en la historia social de los actores subalternos coloniales (Guedes y Fragoso, 2016).
Nuestro trabajo se ha concentrado, entonces, en el Libro 1 de matrimonios de indígenas y castas, que abarca el período 1666-1697 con repertorios anuales regulares y sistemáticos. Período que coincide, además, con la coyuntura que hemos definido como marco temporal y problemático de nuestro estudio, abierto con el término del alzamiento indígena de mediados de siglo y el auge posterior de las malocas esclavistas y de la desnaturalización de mapuche-huilliches. Para afinar nuestro análisis se han seleccionado los años 1669, 1674 y 1678, que son los que registran la mayor cantidad de matrimonios de indios "de arriba" en el período (sobre los 15 matrimonios anuales) (Figura 2). Paradójicamente, son los ańos, también, que demarcan una década en que desde Madrid se busca imponer la abolición de esta esclavitud indígena y cuyo corolario será una cédula dictada, justamente, en 1674; pero que se enfrentará en abierta contradicción con el aumento significativo de las capturas, esclavizaciones y traslados de indios a la capital que caracterizaron el gobierno de Juan Henríquez (1670-1682). Se trata de una tendencia que también hemos podido observar en los registros de bautismo para el mismo período y en la misma parroquia, verificando que bajo

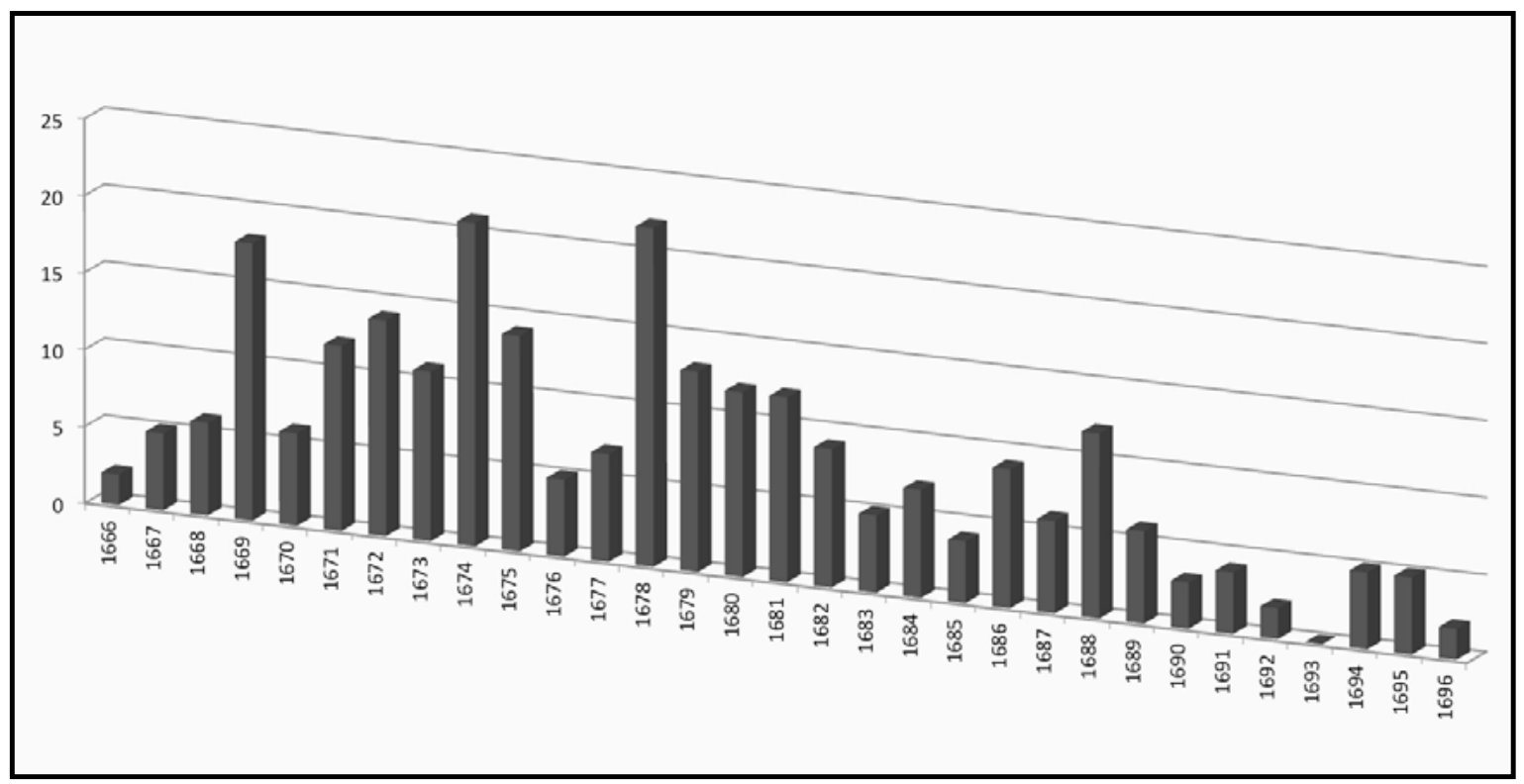

Figura 2. Número de matrimonios con uno o ambos contrayentes originarios "de arriba" (río BiobíoSeno de Reloncaví). Parroquia del Sagrario, Santiago, 1666-1696 (AAS, Sagrario, Matrimonios, 1). 
el gobernador Henríquez aumentan fuertemente los bautismos de indios procedentes del sur del Biobío, coincidiendo su cima también en el año 1674 (Valenzuela Márquez, 2014b).

\section{La fragmentación: entre el desa- rraigo del origen y la clasificación colonial}

Nos hemos referido a las fracturas y desgarros fundamentales con que la guerra maloquera y la consiguiente desnaturalización esclavista afectaron las estructuras e identidades individuales, familiares y comunitarias de los mapuche-huilliches que les sobrevivieron. Fragmentación que luego continuaba en la lejanía -geográfica y psicológica- respecto del lugar de origen, y en la condición colonial y radicalmente diferente del espacio que recibía y redefinía las vidas de estos deportados meridionales.

No está de más insistir en la vulnerabilidad específica que dicha condición implicaba en relación con el resto de sujetos con quienes compartían la denominación de "indios", y para los cuales existía un marco de derechos y deberes que (al menos teóricamente) regulaba y resguardaba legalmente su vida. Respecto de los aucaes chilenos, por el contrario, se presenta un vacío notorio que los deja escindidos del universo humano clasificado jurídica y teológicamente como "indios", a los que la Corona debía proteger y cristianizar. Incluso si observamos la actitud que en otros lugares americanos se tenía frente a los "bárbaros" e "infieles" locales, frente a los cuales se ponía énfasis en la necesidad de adoctrinamiento (Acosta, 1987 [1576]; cf. Zeron, 2011, p. 348 y ss.), en el caso de Chile los indios provenientes de aquella macrorregión "de arriba" o "tierra adentro" -más aún si han pasado a ser esclavos- se encontraban en una suerte de limbo, acentuado por el desarraigo espacial y la destrucción radical de sus redes sociales y políticas originarias.

Sin ir más lejos, la cédula de 1608 que autorizó la esclavitud de los indios capturados en la guerra de Arauco no contemplaba ninguna obligación por parte de sus futuros propietarios de adoctrinarlos y cuidarlos, como sí ocurría en el marco de la encomienda -incluso aquella que lindaba con la servi- dumbre, como la que se practicaba en Chile-. Al contrario, el monarca señaló claramente que se trataría de indios que "se alzaron y rebelaron sin tener causa legítima" y que con esto habrían rechazado, ellos mismos, la posibilidad de ser "bien tratados, como vasallos míos [...] negando la obediencia a la Iglesia"; y, más aún, convirtiéndose en "parte perseguidora de la Iglesia y religión cristiana, y que le han negado la obediencia”. Solo los nińos que fuesen menores de la edad legal de esclavización -10 años y medio los hombres; 9 ańos y medio las mujeresdeberían recibir instrucción cristiana bajo la tuición de la persona a quien le serían "entregados". Para el resto, la incorporación al cristianismo pasaría por las decisiones arbitrarias que otros tomaran por él, en función de la condición explícita que la cédula disponía para que "se puedan servir de ellos y venderlos, darlos y disponer de ellos a su voluntad" (Jara y Pinto, 1982-1983, I, pp. 254-256).

Entre estas decisiones se encontraba, casi como un gesto automático, la aplicación del bautismo, como ya hemos insistido, en tanto rito de paso esencial y condición prácticamente obligatoria para poder vivir y convivir en el seno de la sociedad colonial (cf. Prosperi, 2006); situación que también experimentaban bajo la supervisión jesuita los bozales africanos que llegaban a las costas de Brasil o Centroamérica (Bernand, 2001, pp. 60-64; Vila Vilar, 2000, pp. 192-195). De ahí la obsesión jesuita por bautizar mapuches de "tierra adentro" durante sus misiones "volantes", independientemente de que la eficacia del sacramento estuviese limitada a la sola expresión simbólica del rito como mecanismo de salvación (Foerster, 1996). De ahí también que la mayoría de los cautivos de guerra fuesen bautizados ya en su paso por alguno de los fuertes fronterizos donde se encontraban asentados misioneros de la Compañía de Jesús (Arauco y Buena Esperanza, principalmente; aunque hacia mediados del siglo XVII ya se hacían presentes en los fuertes de Boroa, Toltén Bajo y Paicaví, entre otros) (Valenzuela Márquez, 2011).

El bautismo constituye, de esta forma, un rito de paso y, a la vez, de quiebre, pues conlleva, como gesto fundamental, despojar a los individuos de sus nominaciones originarias y asignarles un nombre cristiano-occidental; uno de los quiebres antropológicos más radicales que puede afectar a sujetos 
Tabla 1. Antecedentes y condiciones de fragmentación de contrayentes originarios "de arriba” (Río Biobío-Seno de Reloncaví). Parroquia del Sagrario, Santiago, 1669, 1674 y 1678 (AAS, Sagrario, Matrimonios, 1).

\begin{tabular}{|c|c|c|c|c|c|c|c|c|c|}
\hline \multirow[b]{2}{*}{ Años } & \multirow[b]{2}{*}{$\begin{array}{c}\text { TOTAL } \\
\text { Contrayentes } \\
\text { [Matrimonios] }\end{array}$} & \multicolumn{8}{|c|}{ FRAGMENTACIÓN (en contrayentes) } \\
\hline & & $\begin{array}{c}\text { Origen geográfico } \\
\text { desconocido o } \\
\text { genérico }\end{array}$ & $\%$ & $\begin{array}{l}\text { Padres descono- } \\
\text { cidos o "infieles" }\end{array}$ & $\%$ & $\begin{array}{c}\text { s/origen } \\
+ \text { s/padres }\end{array}$ & $\%$ & Esclavos & $\%$ \\
\hline 1669 & $36[18]$ & 15 & 42 & 19 & 53 & 16 & 44 & 11 & 31 \\
\hline 1674 & $40[20]$ & 24 & 60 & 33 & 83 & 24 & 60 & 32 & 80 \\
\hline 1678 & $44[22]$ & 25 & 57 & 30 & 68 & 23 & 52 & 32 & 73 \\
\hline
\end{tabular}

que están viviendo en pleno trauma desatado por la experiencia maloquera y la indefensión física y psicológica que implica su cautiverio y el inminente destierro. Lo anterior explica el hecho de que todo indio que aparezca actuando en algún registro documental oficial -administrativo, judicial o eclesiástico- lo haga bajo un nombre occidental. Se trata de una situación que en otros contextos, como el andino, podía convertirse en parte de una agencia indígena orientada a nuevas estrategias de identidad comunitaria (Bernand, 1989; Medinacelli, 1998 y 2003; Tandeter, 2001); pero que en el caso de nuestros sujetos, por el contrario, constituía una marca de dominación colonial, en forma similar a la de los esclavos africanos (Bernand, 2001, p. 64). Por todo lo anterior, el hecho de que todos los indios que se casaban en Santiago y que provenían "de arriba" lucieran nombres cristianos no puede ser visto como un dato menor y anodino, sino como una señal clara de su fragmentación identitaria.

Como se aprecia en la Tabla 1, para los años seleccionados hemos detectado al menos tres grandes indicios de fragmentación bastante comunes entre los contrayentes originarios del sur del río Biobío. La esclavitud, por cierto, es un antecedente definitivo e incuestionable, que se presenta como un estatus social -no solo laboral- al momento de identificar a quienes van a contraer matrimonio; y que, confirmando nuestras hipótesis relacionadas con la coyuntura escogida, atañen a una gran mayoría de los contrayentes en la década de 1670 (73-80\%).
Junto con la condición de esclavos y esclavas, cerca del 50\% de los contrayentes en 1669 y del $60 \%$ en los años 1674 y 1678 no entregan información explícita sobre su origen geográfico específico. Para el resto de contrayentes que sí indican lugar de procedencia, sin embargo, ello no necesariamente implicaría una asociación directa del individuo con aquel lugar, ni un recuerdo personal de la comunidad de origen, ya que dichas anotaciones generalmente no hacen referencia a sus quiñelob sino a los fuertes o asentamientos hispanos instalados en la zona sur y probablemente cercanos a las regiones donde fueron capturados (Arauco, Villarrica, Valdivia, Purén, Boroa, Chiloé, etc.). De esta forma, estaríamos ante una pérdida generalizada del recuerdo/conocimiento del origen, "olvido" reforzado por este gesto adicional de desarraigo y sumisión colonial en la medida que no serían ellos sino las certificaciones de sus captores o la palabra de sus propios amos (siempre mencionados y muchas veces presentes durante el matrimonio) quienes podrían haber establecido el “origen” geográfico recogido en ese segmento minoritario de partidas. También podría haber ocurrido que los contrayentes hubiesen adoptado dicho origen como propio, situación que también formaría parte de la situación de desarraigo y "olvido" ante la radical transformación de sus vidas. A todo lo anterior hay que agregar el antecedente de que una buena proporción - si no la mayoría- de los indios cautivos y desnaturalizados a Santiago eran niños y niñas, generalmente de muy poca edad, lo que ayudaría a alimentar el olvido, la confusión y la redefinición de sus orígenes y "naturaleza”: Francisco, por 
ejemplo, al casarse en 1674 con Micaela -ambos esclavos- dice que es "natural de Castro o de Valdivia" (AAS, Sagrario, 1, f. 93).

Esta situación era más evidente en el caso de aquel $50-60 \%$ de contrayentes cuya "naturaleza" queda registrada con referencias a un territorio reconocido en forma genérica; es decir, con toda una amplitud $y$ vaguedad que es funcional al desarraigo sufrido y a la estigmatización que conlleva la procedencia de una zona "rebelde" a la monarquía e "infiel" a la religión. Así se repiten referentes como "natural de tierra adentro", "de los indios de guerra", "de los infieles aucaes", "de los aucas de este reino" y, más habitualmente, "de arriba". Se trata, por cierto, de denominaciones que no apuntan a lugares reconocibles, sino a aquel espacio geográfico amplio que se extendía desde el río Biobío al sur, transversal a las reducciones de indios aliados -que en el fondo también eran mapuches y, por lo tanto, "de naturaleza bárbara" - y que continuaba por la costa de Arauco y los llanos interiores hacia las regiones huilliches de Osorno y Valdivia. Un espacio definido a partir de criterios ideológicos que clasificaban y homogenizaban a sus habitantes, borrando geografías reales y reemplazándolas por referentes semánticos que apelaban a aquella "rebeldía" contra la religión y la monarquía que hemos visto en los fundamentos de la cédula de 1608 (Obregón Iturra, 2010). Una nueva "identidad geográfica” que los marcaba desde el momento mismo de su destierro con una representación "superestructural" que definiría su identidad jurídica y, por lo mismo, las denominaciones con que invariablemente aparecerán en los registros parroquiales.

A todo lo anterior debemos agregar un tercer vector de fragmentación que se evidencia en la ausencia de información de los padres de los contrayentes. Como vemos en la Tabla 1, más de la mitad de los sujetos declara desconocer a sus padres o -en directa relación con el peso ideológico de su tierra de origen- son registrados por el sacerdote como "padres infieles" o "padres gentiles". Por cierto, en estricto rigor no serían metodológicamente equivalentes la condición de "padre infiel" y la de "padre desconocido"; pero esta relación se evidencia al cruzar esa variable con las anteriores y percibir que al registrar "padre desconocido" el sacerdote apunta claramente a que dicho "desconocimiento" sería consecuencia directa del desapego temprano y forzado asociado a la desnaturalización esclavista. Sin duda estamos ante uno de los indicios más claros y brutales de la fractura comenzada con el ataque maloquero a la comunidad de proveniencia y continuada en la destrucción de redes, memorias e identidades que conllevó el proceso vivido por cada individuo con posterioridad, hasta este momento en que acude $-\mathrm{O}$ es llevado- al matrimonio, en el corazón hispano de la capital del reino de Chile. Olvido e "infidelidad" intrínseca de unos padres cuyo mayor nivel de anonimato se alcanza, justamente, en esos años de auge esclavista de 1674 (83\%) y 1678 (68\%); y que, combinado con el desconocimiento u olvido -real o impuesto- de la "naturaleza" de origen, nos lleva a un escenario donde la mayoría de los contrayentes se presentan desconectados de sus raíces geográficas, sociales y familiares, habiendo experimentado un profundo desarraigo en su deportación a tierras extrańas, y viviendo bajo el estatus de esclavo y el estigma "étnico" que los situaba en aquella alteridad hostil e inferior que provenía de las tierras "bárbaras" del sur.

\section{Las tendencias de “desfragmentación” a la luz de los vínculos matrimoniales}

El matrimonio católico no solo constituye una plataforma significativa para el estudio de aquellos elementos que hemos visto marcan el estado fragmentado en que se encuentran las identidades y conciencias de los indios desnaturalizados que llegan a casarse en la capital chilena. Sus registros también permiten estudiar el papel que cumplen estos y otros ingredientes como conectores de historias parecidas y elementos vinculantes entre los nuevos cónyuges. Por ello utilizamos en sentido figurado el concepto de "desfragmentación", que forma parte del lenguaje computacional y que designa el procedimiento tecnológico mediante el cual los archivos de un disco duro (hard drive), que durante los procesos de escritura y borrado han quedado fragmentados y dispersos, ahora se acomodan y ordenan de tal manera que sus diferentes trozos queden en forma contigua y agrupados según características comunes y condiciones similares (Figura 3). 

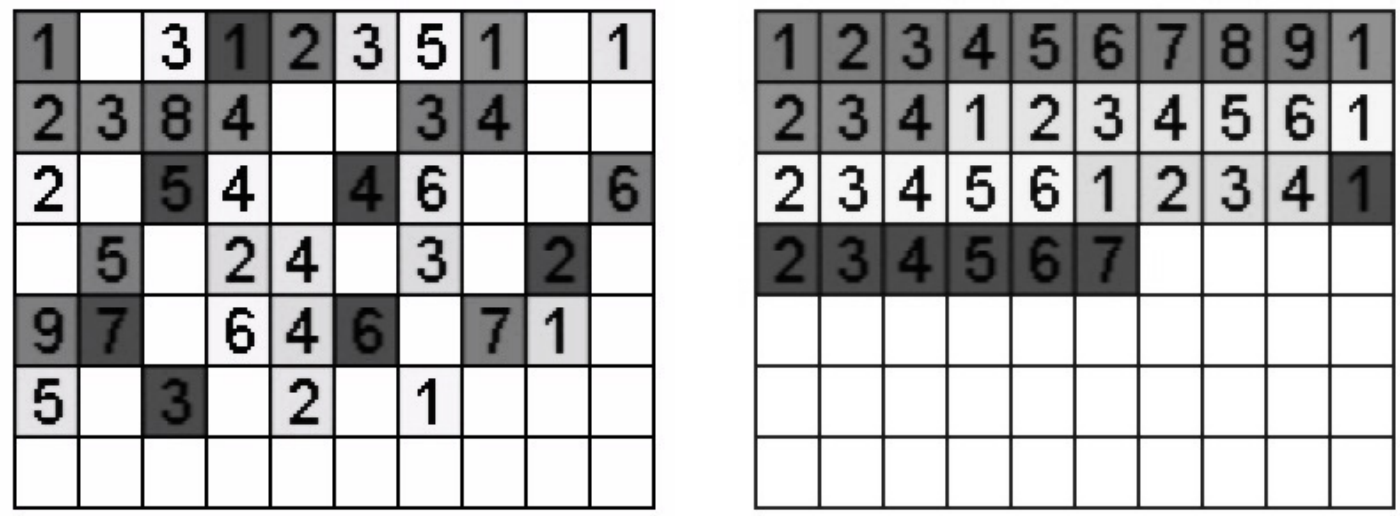

Figura 3. Esquema que muestra las fases inicial y final del proceso de desfragmentación de los archivos en un disco computacional (https://commons.wikimedia.org/wiki/File:Defragmenting_disk.gif).

Hemos organizado en la Tabla 2 todos aquellos elementos, situaciones y condiciones en que se encuentran los contrayentes "de arriba" que acuden a casarse a la parroquia del Sagrario y que, a nuestro juicio, fungen como conectores en esta situación de "desfragmentación matrimonial”. A diferencia de la Tabla 1 , aquí la cifra de referencia será la de matrimonios -no de contrayentes- pues interesa dar cuenta justamente de aquellos elementos vinculantes. Por lo mismo, una primera constatación que surge del procesamiento de estos datos es la baja proporción de casamientos donde no existe este tipo de maridaje entre los contrayentes; es decir, que no poseen ningún vínculo de desfragmentación ( 9 de 18, en 1669; 4 de 20, en 1674; y 8 de 22, en 1678). En otras palabras, la mayoría de los enlaces donde uno o ambos cónyuges provienen "de arriba" participan de una o varias de aquellas condiciones de fragmentación previa que, en el contexto del matrimonio, se constituyen -según nuestra hipótesis- en canales de atracción, mostrando con ello una tendencia hacia uniones en las que el fenómeno de la desnaturalización y sus diferentes consecuencias que hemos visto en los acápites previos constituyen los principales vectores relacionales.

El primero de aquellos que hemos denominado como "vínculos de desfragmentación", y que es prácticamente absoluto, es la condición de "indio" -de arriba- de ambos contrayentes. Del total de 60 matrimonios indígenas registrados en esos tres años, y donde uno o ambos contrayentes provenían "de arriba", solo en tres de ellos el cónyuge masculino fue anotado como "mulato", lo que indica una muy limitada apertura exogámica a nivel "racial” y, por tanto, del subsecuente mestizaje biológico -al menos en este nivel de uniones sacramentadas-. Y ello pese a estar en un contexto urbano donde lo que prima es la diversidad socioétnica y la pluralidad de individuos no hispanos y forasteros, producto de migraciones lejanas o traslados cercanos; experiencia que en principio debiera fomentar la tendencia hacia las mezclas biológicas, tan características de las ciudades iberoamericanas. ${ }^{5}$ De hecho, como se ha estudiado para otros lugares, las estrategias exogámicas de selección de cónyuges entre sujetos subalternos eran vistas como posibilidades de movilidad social; y, por lo mismo, la convivencia y las uniones formales entre indios, mestizos y africanos o afrodescendientes eran comunes y frecuentes en otros espacios urbanos del continente (Grubessich, 1992; Schwartz, 1992, pp. 138-160; Zacca, 1997; Cosamalón Aguilar, 1999; Zúñiga, 2000; García y Ramos Medina, 2001; San Martín,

5 Un acercamiento a la bibliografía que ha tratado estos temas para América colonial se puede ver en nuestro estudio sobre el mundo indígena urbano de Santiago, su diversidad y estrategias de inserción y movilidad colonial: Valenzuela Márquez, 2014a. Para el conjunto del valle central chileno, véanse los datos que aporta Ruiz Rodríguez, 1998. Cf. Calvo, 1984; Lavallé, 1999; Castillo, 2008; Tandeter, 2001. 


\begin{tabular}{|c|c|c|c|c|}
\hline ఫે & $\underset{\widehat{A}}{\vec{A}}$ & बे̆ & 胥 & \multirow{17}{*}{ 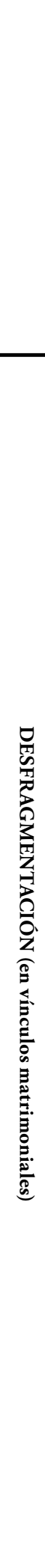 } \\
\hline N & $\tilde{o}$ & $\vec{\infty}$ & 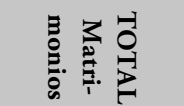 & \\
\hline$\underset{N}{\stackrel{\infty}{N}}$ & $\underset{\sim}{\stackrel{N}{\sigma}}$ & $\underset{\infty}{\stackrel{2}{2}}$ & 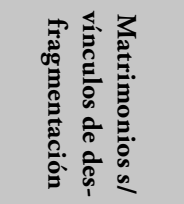 & \\
\hline$\simeq$ & $\varpi$ & 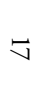 & 를 & \\
\hline vi & vi & $\stackrel{2}{\perp}$ & $\partial^{\circ}$ & \\
\hline$=$ & $\vec{v}$ & $A$ & 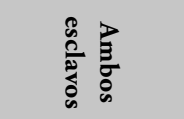 & \\
\hline Ŭ & $\checkmark$ & N & $a^{\circ}$ & \\
\hline$\vec{N}$ & $\bar{N}$ & $v$ & 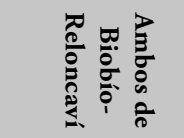 & \\
\hline 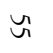 & oิ & w్రు & $\circ^{\circ}$ & \\
\hline$\infty$ & $\bullet$ & $A$ & 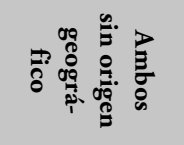 & \\
\hline$\tilde{a}^{\prime}$ & 出 & N & $a^{\circ}$ & \\
\hline$a$ & $\bullet$ & A & 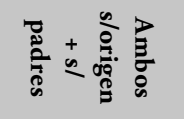 & \\
\hline 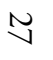 & ثे & $N$ & $a^{\circ}$ & \\
\hline$\checkmark$ & $\vec{\omega}$ & $u$ & 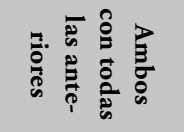 & \\
\hline$\underset{\sim}{\sim}$ & ज & $\underset{\infty}{\sim}$ & $\circ^{\circ}$ & \\
\hline$\infty$ & $\vec{A}$ & $u$ & 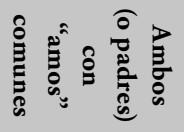 & \\
\hline డ్ & d & $\underset{\infty}{\sim}$ & $a^{0}$ & \\
\hline
\end{tabular}

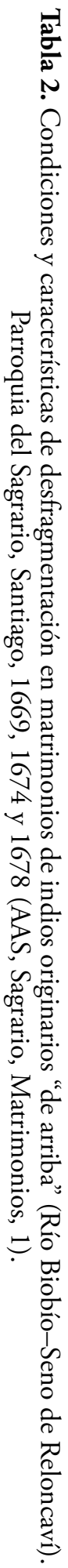


2006; Olivero Guidobono, 2009; Ghirardi y Volpi Scott, 2015, parte II). ${ }^{6}$

Una primera hipótesis para esta suerte de orientación endogámica en la atracción de los contrayentes podría encontrarse en eventuales estrategias de acercamiento por reconocimiento de una zona de origen y condiciones de desarraigo y esclavización comunes. Esta tendencia, frecuente en una experiencia de diáspora como la que estudiamos, caracterizó por ejemplo a las "piezas" africanas llegadas al norte del Perú durante este mismo siglo, y para quienes la generación de sus nuevos parentescos americanos pasaba muchas veces por reconocer afinidades en orígenes étnicos similares (escarificaciones, lenguaje, creencias, etc.) (O’Toole, 2012, pp. 35-38).

Otra explicación para estas vinculaciones endogámicas pasaría por el sentido contrario; esto es, por la eventual incapacidad de los contrayentes para elegir libremente a su cónyuge. La legislación canónica repetía incansables amenazas de excomunión en todos sus concilios generales y sínodos provinciales contra quienes dificultasen o impidiesen que sus esclavos, criados o indios de servicio contrajeran libremente

6 En el contexto lusoamericano de la segunda mitad del XVIII, específicamente para la nueva Capitanía de Rio Grande de São Pedro (en el extremo sur de Brasil), incluso se llegaron a fomentar los matrimonios entre indios -o más bien indias-y blancos, como un gesto político de mestizaje emanado desde la propia monarquía. Se trataba de una región que hasta hacía poco había estado bajo dominio español, que contaba con una población indígena suficientemente cristianizada y asentada en aldeias o reducciones jesuitas, y para lo cual la Corona estipulaba incentivos concretos como dar de baja del servicio militar y asentar como colonos a los soldados que optaran por casarse con una india local: Frühauf García, 2009, pp. 87-89. Más de un siglo antes, y para la misma macrorregión guaranítica donde se incluían estas y otras numerosas reducciones-misiones, algunos tratados apuntaban, por el contrario, al fortalecimiento de los matrimonios endogámicos (solo entre indios; y entre guaraníes, específicamente) como una manera de preservar la conversión y los cambios culturales que las misiones estarían logrando en dicho espacio nativo pretendidamente "cerrado". Véase, por ejemplo, "Apología en defensa del valor de los matrimonios de los indios guaraníes” (1627), AGN. Manuscritos BN, leg. 89, pza. 79; "Parecer del P. Lupercio sobre los matrimonios de los indios guaraníes" (22 de octubre de1645), AGN. Manuscritos BN, leg. 287, pza. 4307. este sacramento (cf. Lobo Guerrero, 1987 [1613], p. 191); e incluso para el universo de los esclavos africanos existía la normativa que desde el Medioevo defendía su facultad para contraer el vínculo aun contra la voluntad de sus propietarios - pudiendo seguir siendo esclavos de diferentes amos- (Martínez Ferrer, 2011, p. 87). Pero en el caso de los indios desnaturalizados de Chile meridional, podían primar las decisiones o elecciones tomadas por otros, sobre todo considerando la vulnerabilidad en que se encontrarían aquellos desterrados, dentro de una lógica esclavista que -como sucedía por esos mismos años en la región brasilera de Bahía- hacía prevalecer los intereses y objetivos de los amos en materia de matrimonio y concubinato de sus subordinados (De CastelnauL'Estoile, 2010; cf. Graham, 2005). Así lo denunciaba el Sínodo del Obispado de Santiago de 1688:

La codicia, vicio familiar en los hombres, ha introducido en los vecinos, por no privarse del servicio de las indias, el estorbarles los casamientos [...], permitiéndoles antes el que vivan amancebadas, por no perderlas. $\mathrm{Y}$ aunque por la sinodal de esta ciudad y por los concilios limenses les está prohibido, pena de excomunión mayor, el impedir la libertad en los matrimonios, así a indios e indias, como esclavos y esclavas, o bien negándoles del todo la licencia o violentándolos, para que se casen con otros, o amedrentándolos con amenazas, castigos y prisiones, y sin temor de la ofensa de Dios y de las penas en que incurren, prosiguen en estos desórdenes (Carrasco, 1983 [1688], p. 61).

Por lo tanto, es importante considerar como otro "vínculo desfragmentador" la existencia de amos en común entre los contrayentes. Como podemos apreciar en la última columna de la Tabla 2, se ha podido constatar que en al menos un tercio de los matrimonios efectuados en 1669 y 1678, ambos cónyuges -o sus padres- "pertenecían" o servían al mismo "amo". Proporción que se eleva al $70 \%$ durante el año 1674 en que asistimos a uniones probablemente organizadas por los propietarios de indios esclavizados y/o adquiridos recientemente, como los tres matrimonios que el mismo 29 de julio de ese año vinculan a tres hombres con tres mujeres, 
todos ellos provenientes de la región de ValdiviaOsorno y esclavos del maestre Diego de Lara, quien desde 1663 ejercía importantes funciones militares en... Valdivia (AAS, Sagrario, Matrimonios 1, f. 9696v; Guarda 1979, p. 103).

El problema amerita un estudio específico y más extenso, por lo que aquí solo queremos apreciar esta dimensión en un par de ejemplos que nos han parecido significativos por las ramificaciones que la historia de los "amos" podría aportar a un estudio de este tipo. El matrimonio de Pedro y María, llevado a cabo a fines de diciembre de 1674, podría pasar por una unión relativamente exogámica entre un indio esclavo "natural de los aucas de padres infieles" y una india "libre, natural desta ciudad, hija legítima de Andrés y de Elvira”. Dentro de los vínculos previos que hemos definido en la Tabla 2, pues, solo compartirían la condición de "indio". Pero la partida parroquial agrega otra información valiosa: los padres de María eran indios de la encomienda de don Antonio de Rojas. Éste era un activo hombre de negocios y prominente estanciero en Colchagua (200 $\mathrm{km}$ al sur de Santiago), cuya carrera política la había desarrollado como vecino de la capital y miembro de su Cabildo, donde llegaría a ser su corregidor en 1676. Ello nos hace lucubrar que quizás Andrés y Elvira laboraban en la estancia rural de Rojas mientras que su hija María pudo haber sido trasladada a Santiago para servir en la casa urbana, pese a ser formalmente "libre". Pues bien, la partida nos informa además que el propietario del indio Pedro era el presbítero Juan de Rojas, hermano de don Antonio y quien llegaría a ser visitador del Obispado de Santiago en 1677. El "vínculo desfragmentador" más importante, en este caso, sería justamente la relación familiar entre el amo del cónyuge y el encomendero de los padres de la esposa (AAS, Sagrario, Matrimonios 1, f. 100v; Muñoz Correa, 1996-1997).

El segundo ejemplo involucra a dos matrimonios llevados a cabo en julio y diciembre de 1678, respectivamente. En el primero de ellos se casaron Manuel y Mencia, quienes no tenían vínculos derivados de condiciones comunes, más allá de ser ambos indios: Manuel, "natural de los aucas, de padres infieles", era esclavo de Juan de Hermúa, cura rector de la catedral de la capital, mientras que Mencia era hija legítima de dos indios de servicio, y provenía de Quillota
(130 km al noroeste de Santiago). No tenían amos en común ni la partida proporciona otros antecedentes que nos permitan sospechar de que no se trate de un matrimonio organizado y definido por una libre elección de los contrayentes (AAS, Sagrario, Matrimonios 1, f. 142v). En diciembre, por su parte, se casaban Antonio Parlaqueo y Juana, ambos indios "de arriba" aunque no esclavos declarados. Antonio estaba al servicio del maestre de campo Alonso de la Cerda, mientras que Juana, si bien de "padre infiel", especificaba que era hija natural de Lucía, india del servicio del abogado de la Real Audiencia Juan de la Cerda. El vínculo a través de los amos parece aquí bastante claro, toda vez que don Alonso era el padre de don Juan -quien, podemos agregar, ya había concertado la unión de una pareja de indios esclavos suyos en 1673- (AAS, Sagrario, Matrimonios 1, f. 87v y 147). Pero la pista de este abogado nos conduce aún más allá, ya que por esos años Juan de la Cerda y Contreras había llegado a ser un letrado muy importante, miembro destacado del Cabildo y en camino a convertirse en uno de los hombres más ricos de Santiago. Se había casado con Mariana de Hermúa, su prima hermana, y este dato nos conecta de inmediato con el matrimonio de los indios Manuel y Mencia que citamos al comienzo del párrafo. En efecto, el amo de Manuel, el sacerdote Juan de Hermúa, resultaba ser entonces primo hermano del licenciado De la Cerda y estaba vinculado al corregimiento de Quillota (de donde provenía la india Mencia) donde en 1685 llegó a adquirir la gran hacienda de La Ligua (Thayer Ojeda, 1989 [1906], pp. 16-17; Ogass, Torres y Camus, 2013, p. 131).

Podríamos agregar, entre los numerosos y ricos registros que se conservan en los libros parroquiales, uno de los escasos matrimonios mixtos que en 1674 unió a la india esclava Lorenza -"natural de arriba, hija de padres infieles"- con el negro esclavo Bartolomé -“criollo natural desta ciudad"-; vínculo que en realidad no sería ejemplo de elección exogámica, sino más bien relacionado con la existencia de un amo en común: don Martín de Urquiza (AAS, Sagrario, Matrimonios 1, f. 91).

El panorama de vínculos que hemos presentado hasta aquí sin duda que se consolida al sumar el factor "esclavitud", pudiendo observar que se trata de un vínculo desfragmentador que fluctúa entre el 50 y el 
$75 \%$ del total de matrimonios de indios "de arriba" durante la década de 1670 . Pero no solo eso, sino que también encontramos para ese mismo período una cantidad mayoritaria de uniones en las cuales ambos contrayentes son originarios de aquella macrorregión que se extiende al sur del Biobío; y que, al mismo tiempo, desconocen su origen geográfico específico y han olvidado o desconocen a sus padres. Todo ello configura una perspectiva bastante lógica en su articulación interna, pues nos lleva a observar como activos conectores de las parejas que se casan aquellos elementos que formaron parte del proceso inicial de fractura y fragmentación de los quiñelob, objeto de las razias maloqueras; elementos que, por lo mismo, habían sido consustanciales a la captura, individualización y deportación de sus miembros.

\section{Para concluir}

A lo largo de este artículo hemos visto diferentes aristas de un proceso significativo para la etnohistoria de Chile durante la época colonial. El siglo XVII delimitó los aspectos y coyunturas más trascendentes de la historia fronteriza que conjugó los desafíos imperiales de la Corona hispana, los intereses de soldados, misioneros, comerciantes y terratenientes locales y, por cierto, la propia historia de los habitantes mapuches y huilliches que habitaban al sur del río Biobío y hasta el seno del Reloncaví. Entre la guerra hispanoindígena desatada en 1598 y las transformaciones que se vislumbran hacia fines de siglo con el declinar de la actividad bélica, el auge progresivo de los intercambios fronterizos y la predilección creciente por la búsqueda de acuerdos en parlamentos y misiones, Chile meridional experimenta intensas coyunturas que marcan el devenir de numerosas personas. Concebidos como "enemigos" y "bárbaros por naturaleza", los indios del sur serán objeto de razias esclavistas y traslados forzosos desde muy temprano en el siglo XVI; aunque con la cédula que legalizó la posibilidad de esclavización este proceso se acentuó y terminó transformando la propia Guerra de Arauco en una actividad orientada a su caza (Chamayou, 2012, pp. 39-55).

Como esclavos formales -con certificación legal de captura en acto de guerra- o simplemente como individuos -especialmente niños y jóvenes- raptados de sus comunidades y deportados para servir forzadamente a algún español en labores urbanas de Santiago $\mathrm{u}$ otros trabajos rurales o mineros en Chile central y el centro-norte, el desarraigo y la consecuente fragmentación de sus vínculos parentales, redes familiares y estructuras sociales constituye una base fundamental para entender la situación de indefensión y fragilidad en la que viven luego de experimentar el trauma de la violencia maloquera y la posterior deportación a tierras extrañas y sometidos al trato de amos hispanos.

En este contexto, el matrimonio cristiano de indios desnaturalizados a la ciudad de Santiago y su comarca cercana no solo se perfilaba como un elemento más de fragmentación -al intentar sepultar cualquier resabio de las formas propias de vincularse y de generar estructuras familiares nativas-, sino también, a la vez, como escenario de "desfragmentación" bajo el nuevo contexto de "naturalización" forzada que implicaba la llegada e inserción en la comarca santiaguina. De esta manera, podemos ver que durante la década de 1669-1678 en la realización de matrimonios donde participaron indios "de arriba", se conjugaron una serie de vectores asociados a su experiencia de desarraigo (esclavitud, proveniencia geográfica desconocida o definida sobre la base de estereotipos genéricos, olvido o desconocimiento de los progenitores, existencia de amos en común, etc.) y que ahora, convertidos en los signos de su identidad y memoria, constituían la base de reconocimiento y de formación de las nuevas familias cristianas de los desterrados.

\section{Agradecimientos}

Este artículo forma parte de los resultados del proyecto de investigación FONDECYT Regular 1150614. La versión original, expuesta en el "IV Congreso Internacional de ciencias, tecnologías y culturas" (Santiago, octubre 2015), fue enriquecida posteriormente gracias a la discusión surgida durante las conferencias dictadas en la Universidad de los Andes (Bogotá, abril 2016) y Universidad de Buenos Aires (septiembre 2016), y en la ponencia presentada al "VI Encontro internacional de história colonial” (Salvador de Bahía, septiembre 2016). Agradezco las invitaciones de dichas instituciones y los comentarios de los asistentes, así como las sugerencias de los evaluadores del manuscrito original. 


\section{Referencias citadas}

Acosta, J. de. 1987 [1576]. De procuranda indorum salute. Madrid: Consejo Superior de Investigaciones Científicas.

Amunátegui Solar, D. (1909-1910). Las encomiendas de indijenas en Chile, 2 vols. Santiago: Imprenta Cervantes.

Bernabéu, S. (Coord.). (2010). Poblar la inmensidad: sociedades, conflictividad y representación en los márgenes del Imperio Hispánico (siglos XV-XIX). Málaga: Ediciones Rubeo / CSIC.

Bernand, C. (1989). Estrategias matrimoniales, apellidos y nombres de pila: libros parroquiales y civiles en el sur del Ecuador. En Moreno Yáñez, S. (Comp.). Antropología del Ecuador. Memorias del primer simposio europeo sobre antropología del Ecuador (pp. 223-244). Quito: Abya-Yala.

Bernand, C. (2001). Negros esclavos y libres en las ciudades hispanoamericanas. Madrid: Fundación Histórica Tavera.

Boccara, G. (2007 [1998]). Los vencedores. Historia del pueblo mapuche en la época colonial. Santiago: Ocho Libros I IIAM, Universidad Católica del Norte.

Calvo, T. (1984). Concubinage et métissage en milieu urbain: le cas de Guadalajara au XVIIe siècle. En Bénassy, M.-C., y Saint-Lu, A. (Coords.). La ville en Amérique espagnole coloniale (pp. 147-158). Paris: Presses de la Sorbonne Nouvelle.

Carrasco, B. (1983 [1688]). Sinodos de Santiago de Chile, 1688 y 1763. Madrid / Salamanca: CSIC.

Castillo, N. (2008). Cholula, sociedad mestiza en ciudad india. Un análisis de las consecuencias demográficas, económicas y sociales del mestizaje en una ciudad novohispana (1649-1796). México: Universidad Autónoma Metropolitana, Iztapalapa / Plaza \& Valdés.

Chamayou, G. (2012). Las cazas del hombre. El ser humano como presa, de la Grecia de Aristóteles a la Italia de Berlusconi. Madrid: Errata Naturae Editores.

Contreras Cruces, H. (2009). Encomienda y servicio personal entre las comunidades indigenas de Chile central, 15411580. Tesis de Doctorado en Historia, Universidad de Chile, Santiago.

Contreras Cruces, H. (2017). Indios de tierra adentro en
Chile central. Las modalidades de la migración forzosa y el desarraigo (fines del siglo XVI y comienzos del XVII). En Valenzuela Márquez, J. (Ed.). América en diásporas. Esclavitudes y migraciones forzadas en Chile y otras regiones americanas (siglos XVI-XIX) (pp. 161-196). Santiago: Instituto de Historia, Pontificia Universidad Católica de Chile / RIL / Red Columnaria.

Cosamalón Aguilar, J. (1999). Indios detrás de la muralla. Matrimonios indigenas y convivencia interracial en Santa Ana (Lima, 1795-1820). Lima: Pontificia Universidad Católica del Perú.

De Castelnau-L'Estoile, Ch. (2010). La liberté du sacrement. Droit canonique et mariage des esclaves dans le Brésil colonial. Annales. Histoire, Sciences Sociales, 6, 2010, 1349-1383, Paris.

De Ramón, A. (1978). Historia urbana. Una metodología aplicada. Buenos Aires: Clacso/SIAP-Planteos.

De Ramón, A. (2000). Santiago de Chile (1541-1991). Historia de una sociedad urbana. Santiago: Sudamericana.

Delumeau, J., y Cottret, M. 1996 [1971]. Le catholicisme entre Luther et Voltaire. Paris: Presses Universitaires de France.

Flusche, D., y Korth, E. (1983). Forgotten Females. Women of African and Indian Descent in Colonial Chile, 1535 1800. Detroit: Blaine Ethridge.

Foerster, R. (1996). Jesuitas y mapuches, 1593-1767. Santiago: Universitaria.

Frühauf García, E. (2009). As diversas formas de ser indio. Politicas indigenas e politicas indigenistas no extremo sul da América portuguesa. Rio de Janeiro: Arquivo Nacional.

García, C., y Ramos Medina, M. (Coords.). (2001). Ciudades mestizas. Intercambios y continuidades en la expansión occidental. México: Centro de Estudios de Historia de México.

Ghirardi, M., e Irigoyen López, A. (2009). El matrimonio, el Concilio de Trento e Hispanoamérica. Revista de Indias, 246, 241-272, Madrid.

Ghirardi, M., y Volpi Scott, A. (Coords.). (2015). Familias históricas. Interpelaciones desde perspectivas iberoamerica- 
nas a través de los casos de Argentina, Brasil, Costa Rica, España, Paraguay y Uruguay. São Leopoldo: Oikos / Editora UNISINOS.

Giudicelli, C. (Ed.). (2011). Fronteras movedizas. Clasificaciones coloniales y dinámicas sociopoliticas en las fronteras de las Américas. México: CEMCA / El Colegio de Michoacán.

Goicovich, F. (2003). En torno a la asimetría de los géneros en la sociedad mapuche del período de la conquista hispana. Historia, 36, 159-178, Santiago.

Goody, J. (1986). La evolución de la familia y el matrimonio en Europa. Barcelona: Herder.

Graham, S. L. (2005). Caetana diz não. História de mulheres da sociedade escravista brasileira. São Paulo: Companhia das Letras.

Grubessich, A. (1992). Esclavitud en Chile durante el siglo XVIII: el matrimonio como una forma de integración social. Revista de historia, 2, 115-137, Concepción.

Gruzinski, S. (1980). Matrimonio y sexualidad en México y Texcoco en los albores de la conquista o la pluralidad de los discursos. En Alberró, S. (Ed.). Seis ensayos sobre el discurso colonial relativo a la comunidad doméstica (pp. 19-76). México: INAH.

Guarda, G. (1979). La sociedad en Chile austral antes de la colonización alemana, 1645-1845. Santiago: Andrés Be1 lo.

Guedes, R., y Fragoso, J. (Orgs.). (2016). História social em registros paroquiais (Sul-Sudeste do Brasil, séculos XVIII$X I X)$. Rio de Janeiro: Mauad.

Hanisch, W. (1981). Esclavitud y libertad de los indios de Chile, 1598-1696. Historia 16, 5-65, Santiago.

Hausberger, B. (2004). La conquista jesuita del noroeste novohispano. Memoria americana. Cuadernos de etnohistoria, 12, 131-168, Buenos Aires.

Inostroza Ponce, X. (2013). Políticas matrimoniales y prácticas indígenas. Doctrina de Belén, Altos de Arica (17631823). Allpanchis, 81-82, 245-278, Cuzco.

Inostroza Ponce, X. (2014). Matrimonio y familia en sociedades andinas: propuestas desde la reconstitución de familias de Santiago de Tacrama o Belén. Altos de Arica, Virreinato del Perú (1763-1820). Historia, 47(1), 65-90, Santiago.

Jara, A. 1984 [1961]. Guerra y sociedad en Chile. Santiago: Universitaria.

Jara, A., y Pinto, S. (Comps.). (1982-1983). Fuentes para la historia del trabajo en el reino de Chile. Legislación, 15461810, 2 vols. Santiago: Andrés Bello.

Konetzke, R. (1946). Documentos para la historia y crítica de los registros parroquiales en las Indias. Revista de Indias, 7, 581-586, Madrid.

Lacoste, J.-Y. (Dir.). (1998). Dictionnaire critique de théologie. Paris: Presses Universitaires de France.

Lamana Ferrario, G. (Ed.). (2012). Pensamiento colonial critico. Textos y actos de Polo Ondegardo. Cuzco: Centro de Estudios Regionales Andinos Bartolomé de Las Casas / Instituto Francés de Estudios Andinos.

Latasa, P. 2008. Publicidad y libertad en el matrimonio: autoridad paterna y dispensa de amonestaciones en Lima, 1600-1650. En Usunáriz, J. M., y García Bourrellier, R. (Eds.). Padres e hijos en España y el mundo hispánico (pp. 53-67). Madrid: Visor.

Latasa, P. (2016). 'If They Remained as Mere Words': Trent, Marriage, and Freedom in the Viceroyalty of Peru, Sixteenth to Eighteenth Centuries. The Americas: A Quarterly Review of Latin American History, 73-1, 1338, New York.

Lavallé, B. (1999). ¿Estrategia o coartada? El mestizaje según los disensos de matrimonio en Quito (1778-1818). En Lavallé, B. (Comp.). Amor y opresión en los Andes coloniales (pp. 113-136). Lima: IFEA / Universidad Ricardo Palma / IEP.

Lavrín, A. (Ed.). (1991). Sexualidady matrimonio en la América hispánica: siglos XVI-XVIII. México D. F.: Grijalbo.

Lázaro Ávila, C. (1997). Las fronteras de América y los "Flandes Indianos". Madrid: Consejo Superior de Investigaciones Científicas.

Lobo Guerrero, B. (1987 [1613]). Sinodos de Lima de 1613 y 1636. Madrid / Salamanca: CSIC. 
Mariño de Lobera, P. / Escobar, B. 1960 [c.1580/1584]. Crónica del reino de Chile. En Esteve Barba, F. (Ed.). Crónicas del reino de Chile. Madrid: Biblioteca de Autores Españoles.

Martínez Ferrer, L. (2011). La defensa de la libertad de indios y negros para contraer matrimonio en el Tercer Concilio Mexicano (1585). En De Zaballa Beascoechea, A. (Ed.). Los indios, el Derecho Canónico y la justicia eclesiástica en la América virreinal (pp. 85-105). Madrid / Frankfurt am Main: Iberoamericana / Vervuert.

Martini, M. (1993). El indio y los sacramentos en Hispanoamérica colonial: circunstancias adversas y malas interpretaciones. Buenos Aires: PRHISCO / CONICET.

Matienzo, J. de (1967 [1567]). Gobierno del Perú. París / Lima: Institut Français d'Études Andines.

Medina, J. T. (Comp.). (1956-1982). Colección de documentos inéditos para la historia de Chile, desde el viaje de Magallanes hasta la batalla de Maipo, 1518-1818. Segunda serie. Fondo Histórico y Bibliográfico José Toribio Medina, 7 vols., Santiago.

Medinacelli, X. (1998). Nombres personales: ¿un objeto o un instrumento de análisis? Revista de la Coordinadora de Historia, 2, 47-64, La Paz.

Medinacelli, X. (2003). Identidad y localidad en los nombres personales indígenas. Sakaka en el siglo XVII. En Lorandi, A. M., Salazar-Soler, C., y Wachtel, N. (Comps.). Los Andes: cincuenta años después (1953-2003). Homenaje a John Murra (pp. 207-228). Lima: Pontificia Universidad Católica del Perú.

Mellafe, R. (1986). Demografía histórica de América Latina. Fuentes y métodos. En Mellafe, R. (Ed.). Historia social de Chile y América. Sugerencias y aproximaciones (pp. 146-215). Santiago: Universitaria.

Muñoz Correa, J. G. (1996-1997). Rojas Puebla, una familia del siglo XVII en la costa de Colchagua. Revista de Estudios Históricos, 40, 65-116, Santiago.

Obregón Iturra, J. (2010). Para acabar con los "indios enemigos"... y también con los "amigos". Los mapuchearaucanos ante las concepciones hispanas de alianzas y antagonismos (Chile, 1670-1673). En Araya, A., y Valenzuela, J. (Eds.). América colonial. Denominaciones, cla- sificaciones e identidades (pp. 173-199). Santiago: RIL / Universidad de Chile / P. Universidad Católica de Chile.

Obregón Iturra, J. y Zavala, J.M. (2009). Abolición y persistencia de la esclavitud indígena en Chile colonial: estrategias esclavistas en la frontera araucano-mapuche. Memoria americana, 17, 7-31, Buenos Aires.

Ogass Bilbao, C., Torres Cañete, R., y Camus Gayán, P. (2013). Apuntes metodológicos para el entrecruzamiento de fuentes históricas a través de sistemas de información geográfica: el caso de Santiago de Chile (1650-1700). Revista de geografía Norte Grande, 55, 125-140, Santiago.

Olivero Guidobono, S. (2009). Matrimonio en Indias: relaciones interétnicas en Buenos Aires (siglo XVIII). En García Bernal, M. C., y Olivero Guidobono, S. (Coords.). El municipio indiano: relaciones interétnicas, económicas y sociales. Homenaje a Luis Navarro García (pp. 565-579). Sevilla: Universidad de Sevilla.

Osante, P. (2010). El septentrión novohispano: una secular colonización hispana. En Bernabéu, S. (Coord.). Poblar la inmensidad: sociedades, conflictividad y representación en los márgenes del Imperio Hispánico (siglos XV-XIX) (pp. 43-105). Málaga: Ediciones Rubeo / CSIC.

O'Toole, R. S. (2012). Bound Lives. Africans, Indians, and the Making of Race in Colonial Peru. Pittsburgh: University of Pittsburgh Press.

Pizzigoni, C. (2004). "Para que le sirva de castigo y al pueblo de exemplo". El pecado de poligamia y la mujer indígena en el valle de Toluca (siglo XVIII). En Gonzalbo Aizpuru, P., y Ares Queija, B. (Coords.). Las mujeres en la construcción de las sociedades iberoamericanas (pp. 193218). Sevilla / México D.F.: Escuela de Estudios Hispano-Americanos / El Colegio de México.

Prosperi, A. (2006). Battesimo e identità cristiana nella prima età moderna. En Prosperi, A. (Ed.). Salvezza delle anime, disciplina dei corpi. Un seminario sulla storia del battesimo (pp. 1-65). Pisa: Scuola Normale Superiore.

Prosperi, A. (2008). El Concilio de Trento. Una introducción histórica. Valladolid: Junta de Castilla y León.

Rabell, C. (1990). La población novohispana a la luz de los registros parroquiales: avances y perspectivas de investigación. México D.F.: UNAM. 
Ragon, P. (1992). Les indiens de la découverte. Évangélisation, marriage et sexualité. Méxique, XVIe siècle. Paris: Éditions L'Harmattan.

Reséndez, A. (2017). La cruzada antiesclavista y las fronteras del imperio español, 1660-1690. En Valenzuela Márquez, J. (Ed.). América en diásporas. Esclavitudes y migraciones forzadas en Chile y otras regiones americanas (siglos XVI-XIX) (pp. 295-318). Santiago: Instituto de Historia, Pontificia Universidad Católica de Chile / RIL / Red Columnaria.

Ruiz Rodríguez, C. (1998). Presencia de los mapuche-huilliche en Chile central en los siglos XVI-XVIII. Desarraigo y mestizaje. Boletín del Museo y Archivo Histórico Municipal de Osorno, 4, 1-71, Osorno.

San Martín, W. (2006). Presencias africanas en Chile. Circulaciones, relaciones pluriétnicas y emergencias culturales afromestizas. Siglos XVII-XVIII. En Seminario Simon Collier 2006 (pp. 289-324). Santiago: Pontificia Universidad Católica de Chile.

Schwartz, S. (1992). Slaves, Peasants, and Rebels. Reconsidering Brazilian Slavery. Chicago: University of Illinois Press, Urbana / Chicago.

Tandeter, E. (2001). Parentesco y estrategias matrimoniales indígenas. En Boleda, M. (Comp.). Población y sociedad en América Latina. Salta: Universidad Nacional de Salta.

Thayer Ojeda, L. (1989 [1906]). Origenes de Chile: elementos étnicos, apellidos, familias. Santiago: Andrés Bello.

Valenzuela Márquez, J. (2009). Esclavos mapuches. Para una historia del secuestro y deportación de indígenas en la Colonia. En Gaune, R., y Lara, M. (Eds.). Historias de racismo y discriminación en Chile (pp. 225-260). Santiago: Uqbar Editores.

Valenzuela Márquez, J. (2011). Misiones jesuitas entre indios "rebeldes": límites y transacciones en la cristianización mapuche de Chile meridional (siglo XVII). En Wilde, G. (Ed.). Saberes de la conversión. Jesuitas, indigenas e imperios coloniales en las fronteras de la cristiandad (pp. 251-272). Buenos Aires: Editorial SB.

Valenzuela Márquez, J. (2014a). Indios urbanos: inmigraciones, alteridad y ladinización en Santiago de Chile (siglos XVI-XVII). Historia crítica, 53, 13-34, Bogotá.
Valenzuela Márquez, J. (2014b). Indios de Arriba en Santiago de Chile según los registros de bautismo: entre el auge esclavista, la reconstrucción urbana y el abolicionismo, 1665-1685. Chungara. Revista de Antropología Chilena, 46 (4), 625-636, Arica.

Valenzuela Márquez, J. (2015). "Diaspora” des indiens des Andes et "dénaturalisation" des indiens de l'Araucanie: deux cas d'immigration et de catégorisation indiennes dans la formation du Chili colonial. Diasporas, 25, 105119, Toulouse.

Valenzuela Márquez, J. (2016). Misionando en los extremos de América: para un estudio comparado de las "fronteras jesuitas” entre los Hurones del Québec y los Mapuches de la Araucanía (siglo XVII). En Rolle, C. (Ed.). El Orbe Católico. Transformaciones, continuidades, tensiones y formas de convivencia entre centro y periferia (siglos XIV-XIX). Santiago: RIL / Instituto de Historia, Pontificia Universidad Católica de Chile.

Valenzuela Márquez, J. (2017). Indias esclavas ante la Real Audiencia de Chile (1650-1680): los caminos del amparo judicial para mujeres capturadas en la guerra de Arauco. En Valenzuela Márquez, J. (Ed.). América en diásporas. Esclavitudes y migraciones forzadas en Chile y otras regiones americanas (siglos XVI-XIX) (pp. 319-380). Santiago: Instituto de Historia, Pontificia Universidad Católica de Chile / RIL / Red Columnaria.

Vicuña Guengerich, S. (2015). Capac Women and the Politics of Marriage in Early Colonial Peru. Colonial Latin American Review, 24(2), 147-167.

Vila Vilar, E. (2000). La evangelización del esclavo negro y su integración en el mundo americano. En Ares, B., y Stella, A. (Eds.). Negros, mulatos, zambaigos: Derroteros africanos en los mundos ibéricos (pp. 189-206). Sevilla: Consejo Superior de Investigaciones Científicas / Escuela de Estudios Hispano-Americanos.

Zacca, I. (1997). Matrimonio y mestizaje entre los indios, negros, mestizos y afromestizos en la ciudad de Salta (1766-1800). Andes, 8, 243-269, Salta.

Zeron, C. (2011). Linha de Fé. A Companhia de Jesus e a escravidão no processo de formação da sociedade colonial (Brasil, séculos XVI e XVII). São Paulo: Editora da Universidade de São Paulo. 
Zúńiga, J.-P. (2000). "Morena me llaman”. Exclusión e integración de los afroamericanos en Hispanoamérica: el ejemplo de algunas regiones del antiguo virreinato del Perú (siglos XVI-XVIII). En Ares, B., y Stella, A. (Coords.). Negros, mulatos, zambaigos: derroteros africanos en los mundos ibéricos. Sevilla: Escuela de Estudios Hispano-Americanos.

Zúñiga, J.-P. (2002). Espagnols d'outre-mer. Émigration, métissage et reproduction sociale à Santiago du Chili, au $17 e$ siècle. Paris: École des Hautes Études en Sciences Sociales.

\section{Fuentes manuscritas utilizadas}

Libros de Matrimonios, Parroquia del Sagrario (Santiago de Chile). Archivo del Arzobispado de Santiago, AAS, Sagrario, 1 (1666-1697).

Colección "Manuscritos relativos a América de la Biblioteca Nacional”. Archivo General de la Nación (Buenos Aires), AGN, Manuscritos BN, legs. 89 y 287. 